\title{
Epocas de Siembra y Fluctuación Poblacional de Afidos en la Producción de Semilla Básica de Papa en Potosí, Bolivia
}

\author{
David Buitrago $^{1}$, Grover Iporre ${ }^{1}$, Víctor Alvarez, \\ Enrique N. Fernández-Northcote ${ }^{2}$
}

\begin{abstract}
Resumen
La demanda de tubérculos-semilla de papa para el área sur de Bolivia es cada vez más creciente especialmente en las categorías altas (Básica). Al contar la Estación Experimental de Chinoli $(3,450 \mathrm{msnm})$ con la posibilidad de riego suplementario para sus parcelas productoras de semilla, se ha realizado el presente trabajo en busca de una mejor época de siembra a fin de escapar a las poblaciones de áfidos vectores de los principales virus de la papa, PVY y PLRV, que afectan a la producción de semilla en estas áreas.

Durante dos campañas agrícolas se estudiaron tres épocas de siembra. La mejor para la producción de tubérculos-semilla fue la primera época de siembra estudiada, a mediados de septiembre. El adelanto de la fecha de siembra a lo acostumbrado en la zona (octubre) permitió la producción de semilla de alta calidad. Los resultados de análisis serológicos confirmaron la alta sanidad de los tubérculos-semilla provenientes de la primera época de siembra escapando a las poblaciones de áfidos transmisores de virus. El monitoreo de las poblaciones de áfidos realizado entre las campañas 1993 a 1997 apoyan esta alternativa. En la campaña 1995-96 no se encontró diferencia estadística entre las tres épocas en estudio en cuanto al rendimiento en peso de tubérculos obteniéndose, sin embargo, un mayor número de tubérculossemilla en la primera época.
\end{abstract}

Aceptado para publicación: octubre 1998.

1 Programa de Investigación de la Papa PROINPA (IBTA-CIP-COSUDE), Potosí, Bolivia. Fax: 062-23764.

2 Programa de Investigación de la Papa PROINPA (IBTA-CIP-COSUDE). Casilla 4285, Cochabamba, Bolivia.

Los autores agradecen la asistencia de la técnica de laboratorio Tatiana Villafane (PROINPA, Cochabamba). 
En la campaña 1996-1997 la segunda y tercera épocas fueron mejores en cuanto a rendimiento y número de tubérculos; sin embargo, la semilla resultó descalificada por incidencia de virosis. El cultivar Revolución rindió más en peso que Imilla Negra y Gendarme en las tres épocas de siembra, no existiendo diferencia en el número de tubérculos.

Palabras claves adicionales: PVY, PLRV.

\title{
Planting Dates and Aphid Incidence in Potato Seed Tuber Production in Potosi, Bolivia
}

\author{
Summary
}

The demand for high quality potato seed tubers (basic seed) is increasing each year in southern Bolivia. PVY and PLRV are the main aphid transmitted viruses, limiting the production of certified potato seed tubers in the established growing seasons. Since it is possible to have supplementary surface irrigation in potato fields at the Chinoli Experimental Station (3,450 masl), the possibility to escape aphid activity by earlier planting dates, and the feasibility of potato basic seed tuber production were studied.

Three planting dates were established during two growing seasons for cultivars Revolution, Imilta Negra, and Gendarme. The best planting date for potato basic seed tuber production was the earlier date in mid September. This planting date, earlier than the one common in the area (October) allowed the production of high quality seed tubers which was confirmed through serology, by escaping from the aphid vectoring activity. The monitoring of the aphid populations between 1993 and 1997 supports this alternative. In the 1995-1996 growing season, yield was not significantly different among the three planting dates. However, there was a significant increase in the number of tubers for the early planting season. In the 1996-1997 growing season, the second and third late planting dates were the best for yield and number of tubers, but the potato seed tuber production was not certified due to virus infection. The yield and number of tubers in the early planting dates were satisfactory and seed tubers met certification requirements. 
Cultivar "Revolución" had higher yield than "Imilla Negra" and "Gendarme" in the three planting seasons, however, there was no significant difference in the number of tubers produced.

Additional index words: PVY, PLRV

\section{Introducción}

En el Departamento de Potosí, existe una demanda real de tubérculossemilla de categoría básica que es insatisfecha. Esto ha sido manifestado en los sondeos participativos en las áreas de impacto Institucional del Instituto Boliviano de Tecnología Agropecuaria (IBTA) y en foros zonales del Departamento de Potosí (7).

En años anteriores se ha observado que en la Estación Experimental de Chinoli en la época normal de cultivo (octubre-abril), los áfidos alados visitantes empiezan a detectarse a mediados de enero iniciándose poblaciones elevadas a partir de la segunda quincena del mes de febrero (1), afectando la calidad de la semilla en producción e imposibilitando su certificación. Esto ocurre asimismo en las Pampas de Lequezana cercanas a la Estación Experimental. Los áfidos son los vectores de los principales virus de la papa (5) que inciden en la zona, el virus $Y(P V Y)$ y el virus del enrollamiento de la hoja de la papa (PLRV).

La fecha de siembra del cultivo, las condiciones climáticas y las medidas de control para los áfidos, así como la susceptibilidad varietal, y el manejo cultural son aspectos importantes para una buena selección del área para producción de semilla de papa. Una fecha adecuada de siembra es importante para la programación de la aplicación de insecticidas, así como para programar las fechas de destrucción del follaje de tal manera de evitar ó reducir la incidencia de virosis transmitidas por áfidos. Para la producción de semilla, son áreas aceptables aquellas en que no hay incidencia de áfidos por su altitud o latitud, o sólo se capturan unos pocos áfidos alados de M. persicae antes del corte de follaje. En muchas áreas productoras de papa es difícil producir semilla antes o después del período crítico de actividades de los áfidos vectores. Sin embargo, en algunos países se ha logrado éxito con 
un adelanto en la época de siembra (2). Se considera que el periodo crítico de incidencia de áfidos visitantes empieza cuando se detecta en una trampa amarilla dos alados de Myzus persicae por día. El corte del follaje deberá ocurrir en los 8 a 10 días siguientes a fin de obtener la máxima calidad de tubérculos-semillas (2). Ese plazo es suficiente para que la infección de virus no llegue a los tubérculos.

Al contar la Estación Experimental de Chinoli con la posibilidad de riego suplementario en las parcelas de producción de semilla, se decidió experimentar con siembras adelantadas, a fin de escapar a la elevada población de áfidos, y que éste adelanto no influyera en el comportamiento del cultivo y en su producción. De esta manera se podría producir semilla de alta sanidad, que permitiría contribuir a satisfacer la demanda local de los cultivares priorizados por las instituciones y agricultores semilleristas.

\section{Materiales y Métodos}

Se dotó de riego suplementario a los ensayos que se llevaron a cabo en terrenos de producción de semilla de la E.E. Chinoli. La Estación se encuentra situada en la Provincia J.M. Linares del Departamento de Potosí a 3,450 msnm, con una precipitación promedio de $355 \mathrm{~mm}$ anuales distribuidos en un $94 \%$ entre los meses de octubre a abril. La mayor incidencia de heladas ocurre entre febrero y septiembre con 81 días de heladas por año (4).

El primer ensayo en Chinoli en la campaña 1995-1996 ocupó una superficie de $600 \mathrm{~m}^{2}$, utilizándose un diseño experimental de bloques completamente al azar en un arreglo factorial de $3 \times 3$ con tres repeticiones. Cada unidad experimental constó de cinco surcos de $5 \mathrm{~m}$ de largo, con 20 plantas por surco distanciadas a $25 \mathrm{~cm}$ entre sí y $0.80 \mathrm{~m}$ entre surcos.

Los factores en estudio fueron:

Épocas de siembra: primera época, 21 de septiembre de 1995 a 23 de febrero de 1996; segunda época, 11 de octubre de 1995 a 23 de febrero de 1996; y tercera época, 31 de octubre de 1995 a 04 de marzo de 1996.

Cultivares: Revolución, Imilla Negra, y Gendarme. El cultivar Revolución es un cultivar introducido del Perú. Los cultivares Imilla Negra y Gendarme son cultivares nativos de Solivia (Solanum tuberosum ssp. andigena). La semilla utilizada fue de categoría prebásica producida en invernaderos de la E.E. Chinoli. 
Para determinar la población de áfidos alados visitantes se colocaron dos trampas amarillas en la parcela experimental (8) a una altura de $40 \mathrm{~cm}$ del suelo, y trampas con feromonas sexuales para la polilla de la papa (3); los áfidos y polillas se recolectaron semanalmente para su conteo.

La producción se rigió a las normas establecidas en campañas anteriores. La verificación sanitaria del material con respecto a virus se efectuó en muestras de tubérculos de cada tratamiento tomadas a la cosecha y analizadas en el laboratorio de virología de la E.E. Toralapa mediante DAS-ELISA (prueba de inmunoadsorción con conjugados enzimáticos, modalidad directa de emparedado de doble anticuerpo) para siete de los principales virus de la papa PVY, PLRV, y los virus de la papa X (PVX), $S$ (PVS), latente andino (APLV), moteado andino (APMV) y virus peruano del tomate variante papa (PTV-P) también reportado como virus $V$ de la papa (PVV). Las muestras se tomaron en campo inmediatamente antes de la cosecha, 10 tubérculos del tamaño III (35 a $44 \mathrm{~mm}$ ) por unidad experimental siguiendo una línea imaginaria en forma de $X$. Los tubérculos (270) se sembraron en macetas al interior de una casa de malla para luego realizar el análisis serológico a los 60 días después de su siembra.

El corte del follaje en las parcelas experimentales se realizó el 6 de febrero para la primera y segunda época y el 16 de febrero para la tercera época de siembra. A la cosecha (tubérculos-semilla de categoría básica I) se tomó el rendimiento en kg y número de tubérculos por unidad experimental, total y por tamaño de tubérculos. Con estos datos se realizó un análisis de variancia y la prueba de Duncan para comparación múltiple de medias $(P=0.05)$.

En la campaña 1995-1996 se estableció un ensayo control en otra parcela de la E.E. Chinoli a $500 \mathrm{~m}$ de separación de la anterior con tres épocas de siembra: 24 de setiembre, 24 de octubre y 20 de noviembre, y los cultivares Sani Imilla (categoría Básica I) y Revolución. La semilla del cultivar Revolución tenía 50\% de infección por PLRV. Al momento de la siembra para la primera época ya se tenían campos adyacentes de haba (Vicia faba) alrededor de un mes de sembrados, en los que se pudo observar la incidencia de áfidos colonizantes. Se usó un diseño experimental de bloques completos al azar con seis tratamientos y cuatro repeticiones. Cada unidad experimental estuvo constituida por cuatro surcos de $5 \mathrm{~m}$ de largo, $0.3 \mathrm{~m}$ de distanciamiento entre plantas y $0.8 \mathrm{~m}$ entre surcos. Las plantas de los dos surcos centrales fueron evaluadas a la floración por sintomatología y ELISA, y a la cosecha, conforme a lo indicado anteriormente. Se colocaron tres bandejas amarillas para el monitoreo de áfidos alados visitantes las que se distribuyeron en el interior de la parcela a una altura de $40 \mathrm{~cm}$ del suelo. El corte de follaje se realizó para la primera época de siembra el 20 de enero y para la segunda y tercera época el 15 de febrero. 
En la campaña 1996-1997 se hizo un seguimiento a la semilla básica I, cosechada en el ensayo de épocas de siembra (Campaña 95-96) de los cultivares Gendarme e Imilla Negra, los que fueron sembrados en época normal de cultivo (10 noviembre 1996 al 4 abril 1997) en la Localidad de Lagunilla, zona tradicionalmente semillera ubicada a una altura de 3,650 msnm. La semilla básica I del cultivar Revolución fue utilizada para otra siembra adelantada (24 de septiembre 1996) en la E. E. Chinoli.

También en la campaña 1996-1997 se estableció un ensayo con tres siembras adelantadas y los cultivares Revolución, Imilla Negra y Gendarme siguiendo el mismo diseño experimental que en la campaña 95-96. Las fechas de siembra fueron, 04 de septiembre, 24 de septiembre y 10 de octubre, para la primera, segunda y tercera época de siembra, respectivamente. El corte de follaje se realizó el 03 de febrero para las tres épocas de siembra, cosechándose a los 40 días después a consecuencia de las excesivas precipitaciones pluviales que perjudicaban el ingreso a las parcelas.

\section{Resultados}

\section{Épocas de siembra - Campaña 1995-1996}

Los primeros áfidos alados se registraron el 13 de febrero, habiendo sido capturados siete días después del corte de follaje (06 febrero) en la primera y segunda época de siembra y tres días antes del corte de follaje (16 febrero) en la tercera época de siembra (Figura 1). La fluctuación poblacional de la polilla de la papa (Phthorimaea operculella) se mostró errática. Las heladas se observaron antes de la emergencia de los cultivares (primera quincena de septiembre) y después de efectuado el corte del follaje (primera quincena de marzo) por lo que no se presentaron problemas por heladas. 


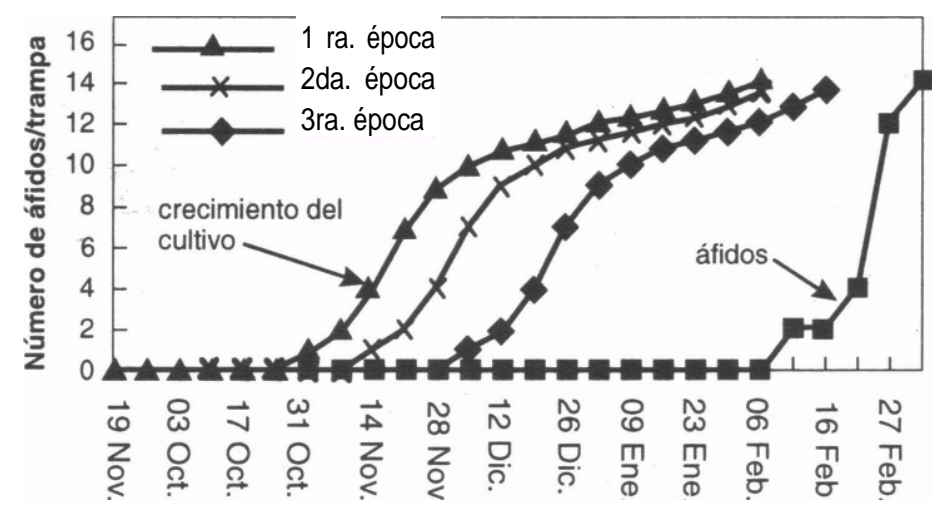

Periodo después de la siembra

Figura 1. Curvas de crecimiento del cultivo y fluctuación poblacional de áfidos en la parcela experimental del cultivo de papa, en tres épocas de siembra. Chinoli 1995-1996.

Considerando el promedio de los tres cultivares, no hubo diferencia significativa en el rendimiento en peso total de tubérculos (Tabla 1) de las tres épocas de siembra, pero hubo diferencias para el número de tubérculos, siendo mayor en la primera y tercera frente a la segunda época.

Tabla 1. Promedios de porcentaje de emergencia, y rendimiento en peso y número total y por categoría de tamaño de tubérculos-semilla en tres épocas de siembra de los cultivares Revolución, Imilla Negra y Gendarme. Chinoli 1995-1996.

\begin{tabular}{|c|c|c|c|c|c|c|c|c|}
\hline \multirow[t]{2}{*}{ Siembra } & \multirow{2}{*}{$\begin{array}{c}\text { Emerg } \\
\%\end{array}$} & \multirow{2}{*}{$\begin{array}{c}\text { Rend. } \\
\text { t/ha }\end{array}$} & \multirow{2}{*}{$\begin{array}{c}\text { No.total/ } \\
20 \mathrm{~m}^{2}\end{array}$} & \multicolumn{5}{|c|}{ No. tubérculos seleccionados por tamaño/20rn ${ }^{2}$} \\
\hline & & & & $\begin{array}{l}>55 \\
\mathrm{~mm}\end{array}$ & $\begin{array}{c}55-45 \\
\mathrm{~mm}\end{array}$ & $\begin{array}{c}44-35 \\
\mathrm{~mm}\end{array}$ & $\begin{array}{c}35-25 \\
\mathrm{~mm}\end{array}$ & $<25 \mathrm{~mm}$ \\
\hline $1^{\text {ra }}$ época & 93 & 16.15 & $917 a^{*}$ & $40 a$ & $121 \mathrm{a}$ & $235 a$ & $442 a$ & $79 a$ \\
\hline $2^{\text {da }}$ época & 94 & 11.82 & $680 \mathrm{~b}$ & $41 a$ & $102 a$ & $180 a$ & $280 \mathrm{~b}$ & $77 a$ \\
\hline $3^{\text {ra época }}$ & 94 & 13.66 & $861 \mathrm{a}$ & $41 a$ & $100 a$ & $242 a$ & $381 a b$ & $97 a$ \\
\hline C.V. \% & 4.77 & 28.41 & 18.82 & 82.89 & 29.61 & 32.39 & 29.60 & 62.49 \\
\hline
\end{tabular}

* Las medias con la misma letra por columna no son significativamente diferentes de acuerdo con la prueba de Duncan para comparación múltiple de medias ( $\mathrm{P}=0.05)$. 
Esto posiblemente se debió a que fueron favorecidos por lluvias en la etapa inicial del cultivo. Además, en la tercera época se cortó el follaje sólo diez días después que en la primera y segunda época.

En lo que respecta al comportamiento de cada cultivar, hubo diferencias significativas en el rendimiento total entre las tres épocas de siembra en los tres cultivares (Tabla 2). Dentro de cada época de siembra el rendimiento del cultivar Revolución fue siempre el mejor en relación a Imilla Negra y Gendarme.

Tabla 2. Rendimiento total (tha) de tres cultivares de papa en tres épocas de siembra. Chinoli 1995-1996.

\begin{tabular}{lllc}
\multicolumn{1}{c}{ Tratamiento } & Revolución & $\begin{array}{c}\text { Rendimiento (t/ha) } \\
\text { Imilla Negra }\end{array}$ & Gendarme \\
\hline $1^{\text {ra }}$ época & 17.26 & 16.67 & 14.52 \\
$2^{\text {da }}$ época & 13.68 & 9.60 & 12.17 \\
$3^{\text {ra }}$ época & 20.39 & 10.37 & 10.23 \\
\hline D.M.S.: 6.28 & & & \\
C.V. \%: 28.41 & & & \\
\hline
\end{tabular}

En la primera época de siembra no se detectó infección por virus en los tubérculos semilla de los cultivares Revolución y Gendarme, sin embargo se detectó en la segunda y/o tercera época. En el cultivar Imilla Negra no se detectó ninguno de los virus analizados en las tres siembras (Tabla 3).

Tabla 3. Incidencia de PLRV y PVY en tres cultivares de papa y en tres épocas de siembra determinadas mediante DAS-ELISA. Campaña 1995-1996

\begin{tabular}{cccc} 
Cultivar & Época de siembra & \% de virus detectado* \\
PLRV & PVY \\
\hline Revolución & $1^{\text {ra }}$ & 0 & 0 \\
& $2^{\text {da }}$ & 0 & 0 \\
Imilla Negra & $3^{\text {ra }}$ & 3 & 0 \\
& $1^{\text {ra }}$ & 0 & 0 \\
Gendarme & $2^{\text {da }}$ & 0 & 0 \\
& $3^{\text {ra }}$ & 0 & 0 \\
& $1^{\text {ra }}$ & 0 & 0 \\
$2^{\text {da }}$ & 0 & 3 \\
& $3^{\text {ra }}$ & 0 & 6 \\
\hline
\end{tabular}

* En plantas provenientes de una muestra de 30 tubérculos-semilla. 


\section{Ensayo Control - Campaña 1995-1996}

En el ensayo control de la Campaña 95-96, se observó incidencia de síntomas virósicos por encima del $10 \%$ sólo en la tercera época de siembra en el cultivar Revolución (Figura 2).

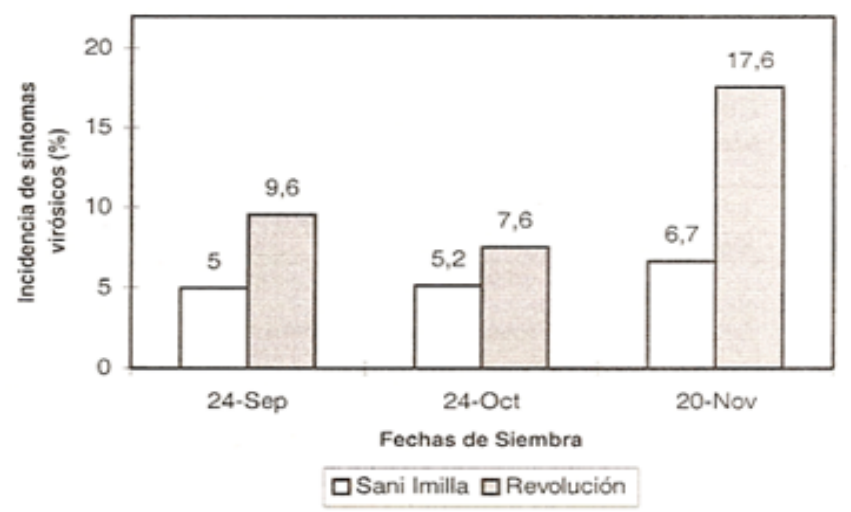

Figura 2. Incidencia de síntomas virósicos, en dos cultivares. Ensayo control campaña 1995-1996.

En el peso y número de tubérculos por categorías, y peso total (Tablas 4 y 5) no se observaron mayores diferencias estadísticas entre las tres épocas de siembra, sin embargo a nivel de cultivares se presentaron diferencias en el peso total. El cultivar Revolución presentó el mayor rendimiento en las tres épocas de siembra.

La población de áfidos alados empezó a detectarse en estas parcelas en la segunda quincena del mes de enero y presentó su mayor población en la segunda quincena del mes de febrero, coincidiendo con la cosecha de la primera época, además del corte del follaje de la segunda época.

El análisis serológico de las plantas provenientes de tubérculos muestreados a la cosecha (Tabla 6) muestra que en el cultivar Sani Imilla se detectó sólo $16 \%$ de infección por PLRV en la primera época de siembra mientras que Revolución tuvo un $11 \%$ de infección por PLRV adicional al $50 \%$ que se detectó originalmente en la semilla utilizada. Estos resultados indican una cierta actividad de transmisión en las 
parcelas de la primera época de siembra debido probablemente a la diseminación de áfidos desde las parcelas de haba a la fuente de inoculo constituido por el cultivar Revolución de este ensayo. En las parcelas de la segunda y tercera época hubo una actividad mayor de diseminación de PLRV debido a que estuvieron expuestas a la transmisión durante más tiempo (casi un mes más) y mayor presión del vector.

Tabla 4. Rendimiento en el ensayo control de épocas de siembra. E. E. Chinoli 1995-1996.

\begin{tabular}{lllllll}
\hline & \multicolumn{5}{c}{ Rendimiento de semilla (t/ha) } \\
\cline { 2 - 6 } Tratamiento & Comercial & $1 \mathrm{ra}$ & $2 \mathrm{da}$ & $3 \mathrm{ra}$ & Descarte & Total \\
\hline $\begin{array}{l}\text { Sani Imilla } \\
1^{\text {ra época }}\end{array}$ & $3.5 \mathrm{a}^{*}$ & $3.0 \mathrm{bc}$ & $4.0 \mathrm{bc}$ & $4.0 \mathrm{bc}$ & $1.6 \mathrm{~b}$ & $16.1 \mathrm{~b}$ \\
$\begin{array}{l}\text { Sani Imilla } \\
2^{\text {da }} \text { época }\end{array}$ & $3.2 \mathrm{a}$ & $4.9 \mathrm{ab}$ & $4.3 \mathrm{abc}$ & $4.1 \mathrm{bc}$ & $2.3 \mathrm{~b}$ & $18.8 \mathrm{~b}$ \\
$\begin{array}{l}\text { Sani Imilla } \\
3^{\text {ra } \text { época }}\end{array}$ & $3.6 \mathrm{a}$ & $2.4 \mathrm{c}$ & $2.6 \mathrm{c}$ & $3.0 \mathrm{c}$ & $2.6 \mathrm{~b}$ & $14.2 \mathrm{~b}$ \\
$\begin{array}{l}\text { Revolución } \\
1_{\text {ra época }}^{\text {Répoción }}\end{array}$ & $3.8 \mathrm{a}$ & $6.6 \mathrm{a}$ & $5.4 \mathrm{ab}$ & $4.4 \mathrm{abc}$ & $3.5 \mathrm{ab}$ & $23.7 \mathrm{a}$ \\
$\begin{array}{l}\text { Revolución } \\
2^{\text {da época }}\end{array}$ & $4.4 \mathrm{ab}$ & $6.7 \mathrm{a}$ & $6.2 \mathrm{a}$ & $5.9 \mathrm{a}$ & $3.5 \mathrm{ab}$ & $26.7 \mathrm{a}$ \\
$\begin{array}{l}\text { Revolución } \\
3^{\text {ra época }}\end{array}$ & $5.4 \mathrm{a}$ & $4.6 \mathrm{~b}$ & $5.0 \mathrm{ab}$ & $5.7 \mathrm{ab}$ & $4.8 \mathrm{a}$ & $25.5 \mathrm{a}$ \\
\hline C.V. \% & 20.6 & 26.8 & 29.2 & 24.0 & 41.5 & 16.8 \\
\hline
\end{tabular}

* Las medias con las mismas letras por columna no son estadísticamente diferentes de acuerdo a la prueba de Duncan para comparación múltiple de medias $(P=0.05)$. 
Tabla 5. Número de tubérculos en el ensayo control de épocas de siembra. E.E. Chinoli 1995-1996.

\begin{tabular}{|c|c|c|c|c|c|}
\hline \multirow[t]{2}{*}{ Tratamiento } & \multicolumn{5}{|c|}{ Número de tubérculos por $7 \mathrm{~m}^{2}$} \\
\hline & Comercial & $\begin{array}{c}\text { Semilla } \\
1 \mathrm{ra}\end{array}$ & $\begin{array}{c}\text { Semilla } \\
2 \mathrm{da}\end{array}$ & Semilla 3ra & Descarte \\
\hline $\begin{array}{l}\text { Sani Imilla } \\
1^{\text {ra época }}\end{array}$ & $23 a^{*}$ & $45 a$ & 63 be & 158 be & $194 \mathrm{~b}$ \\
\hline $\begin{array}{l}\text { Sani Imilla } \\
2^{\text {da }} \text { época }\end{array}$ & $24 a$ & $51 a$ & 61 be & $201 a b$ & $285 a b$ \\
\hline $\begin{array}{l}\text { Sani Imilla } \\
3^{\text {ra época }}\end{array}$ & $20 a$ & $45 a$ & $50 \mathrm{c}$ & $109 c$ & $247 a b$ \\
\hline $\begin{array}{l}\text { Revolución } \\
1^{\text {ra }} \text { época }\end{array}$ & $45 b$ & $73 b$ & $93 a$ & $176 a b$ & $229 a b$ \\
\hline $\begin{array}{l}\text { Revolución } \\
2^{\text {da }} \text { época }\end{array}$ & $37 \mathrm{~b}$ & $76 \mathrm{~b}$ & $101 \mathrm{a}$ & $197 \mathrm{ab}$ & $317 a$ \\
\hline $\begin{array}{l}\text { Revolución } \\
3^{\text {ra }} \text { época }\end{array}$ & $36 \mathrm{~b}$ & $67 \mathrm{~b}$ & $82 a b$ & $224 a$ & $302 a$ \\
\hline C.V. \% & 18.4 & 20 & 20 & 21.7 & 23.8 \\
\hline
\end{tabular}

* Las medias con las mismas letras por columna no son estadísticamente diferentes de acuerdo a la prueba de Duncan para comparación múltiple de medias $(P=0.05)$.

Tabla 6. Incidencia de PLRV y PVY en dos cultivares de papa y tres épocas de siembra determinadas mediante DAS ELISA en tubérculos-semilla cosechados en el ensayo control. E.E. Chinoli. 1995-1996.

\begin{tabular}{|c|c|c|c|c|c|}
\hline \multirow{2}{*}{$\begin{array}{l}\text { Época de } \\
\text { siembra }\end{array}$} & \multirow{2}{*}{$\begin{array}{l}\text { No. plantas } \\
\text { analizadas }\end{array}$} & \multicolumn{2}{|c|}{ No. plantas con } & \multicolumn{2}{|c|}{$\%$ de virus } \\
\hline & & PLRV & PVY & PLRV & PVY \\
\hline \multicolumn{6}{|l|}{ Sani Imilla } \\
\hline $\begin{array}{l}1^{r} \\
2^{\text {da }} \\
3^{\text {ra }}\end{array}$ & $\begin{array}{l}18 \\
17 \\
20\end{array}$ & $\begin{array}{c}3 \\
8 \\
15\end{array}$ & $\begin{array}{l}0 \\
0 \\
0\end{array}$ & $\begin{array}{l}16 \\
47 \\
75\end{array}$ & $\begin{array}{l}0 \\
0 \\
0\end{array}$ \\
\hline \multicolumn{6}{|l|}{ Revolución* } \\
\hline $\begin{array}{l}1^{\text {ra }} \\
2^{\text {da }} \\
3^{\text {ra }}\end{array}$ & $\begin{array}{l}18 \\
20 \\
16\end{array}$ & $\begin{array}{l}11 \\
13 \\
13\end{array}$ & $\begin{array}{l}0 \\
1 \\
0\end{array}$ & $\begin{array}{l}61 \\
65 \\
81\end{array}$ & $\begin{array}{l}0 \\
5 \\
0\end{array}$ \\
\hline
\end{tabular}

* $50 \%$ de los tubérculos-semilla utilizados tenían PLRV.

\section{Seguimiento a la semilla básica I producida en la campaña 1995-1996}

En un seguimiento a la semilla básica I (obtenida de la primera época de siembra) de los cultivares Gendarme e Imilla Negra, del ensayo épocas 
de siembra campaña 95-96, sembradas para su multiplicación en la localidad de Lagunillas, se observó un buen desarrollo vegetativo, con un rendimiento de 12 t/ha para Gendarme y 15 t/ha para Imilla Negra, sin ninguna planta con síntomas de virus. En la E.E. Chinoli donde se realizó una siembra adelantada con el cultivar Revolución básica I (semilla obtenida de la primera época de siembra) del mismo ensayo de la campaña 95-96, se observó también buen desarrollo foliar que se tradujo en un alto rendimiento (35 t/ha). Tampoco se observaron síntomas de virus en las plantas. En esta campaña agrícola 96-97 en la E.E. Chinoli, las poblaciones de áfidos alados comenzaron a fines de enero (Figura 3), alcanzando picos de mayor población en el mes de marzo.

Como resultado del proceso de certificación, la semilla de categoría básica I remultiplicada en campo, tanto en la Localidad de Lagunillas como en la E.E. Chinoli, fue calificada por inspección visual en el campo como semilla de categoría Básica II.

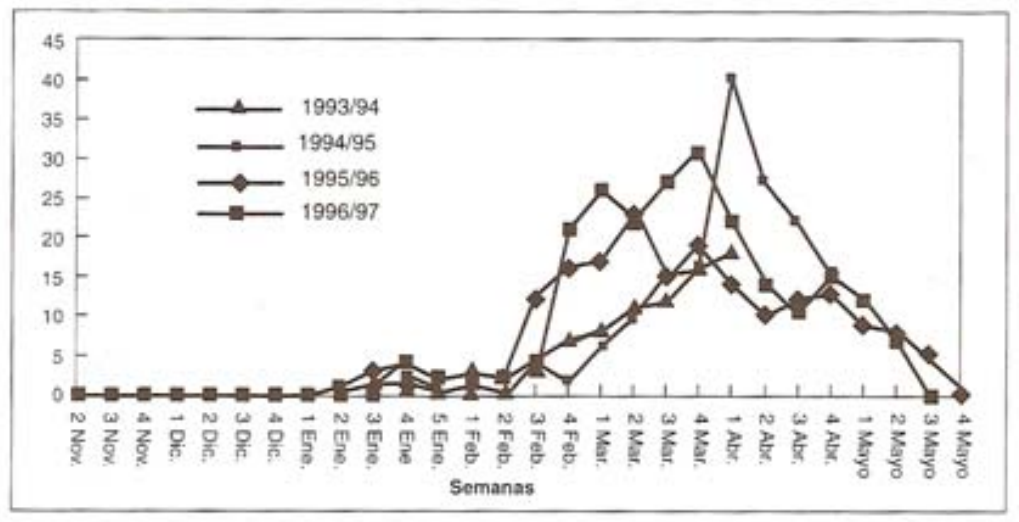

Figura 3. Fluctuación poblacional de áfidos alados durante cuatro campañas agrícolas en las pampas de Lequezana, Potosí.

\section{Siembra adelantada - Campaña 1996-1997}

Considerando el promedio de los tres cultivares, se observó diferencias estadísticas significativas para el número total de tubérculos siendo la tercera época la de mayor número de tubérculos por unidad experimental seguido de la segunda época de siembra (Tabla 7). 
Tabla 7. Emergencia y rendimiento en peso y número total de tubérculos-semilla, y número de tubérculos seleccionados por tamaño en tres épocas de siembra de los cultivares Revolución, Imilla Negra y Gendarme. Chinoli 1996-1997

\begin{tabular}{|c|c|c|c|c|c|c|c|}
\hline \multirow[t]{2}{*}{ Tratamiento } & \multirow{2}{*}{$\begin{array}{c}\text { Emer- } \\
\text { gencia } \\
\%\end{array}$} & \multirow{2}{*}{$\begin{array}{l}\text { Rendi- } \\
\text { miento } \\
\text { t/ha. }\end{array}$} & \multirow{2}{*}{$\begin{array}{c}\text { No. } \\
\text { total } \\
20 \mathrm{~m}^{2}\end{array}$} & \multicolumn{4}{|c|}{$\begin{array}{l}\text { No. de tubérculos seleccionados por tamaño/20 } \\
\qquad \mathrm{m}^{2}\end{array}$} \\
\hline & & & & $>55 \mathrm{~mm}$ & $55-45 \mathrm{~mm}$ & $44-35 \mathrm{~mm}$ & $35-25 \mathrm{~mm}$ \\
\hline $1^{\text {ra }}$ época & 89 & $15.8 \mathrm{~b}$ & 585 b & $70 a$ & $160 a$ & $184 \quad b$ & $171 \quad b$ \\
\hline $2^{\text {da }}$ época & 91 & $20.5 a$ & $747 a b$ & $88 a$ & $194 a$ & $260 \mathrm{a}$ & $205 a b$ \\
\hline $3^{\text {ra }}$ época & 87 & $19.8 a$ & $845 a$ & $84 a$ & $196 a$ & $270 \mathrm{a}$ & $295 \mathrm{a}$ \\
\hline C.V. \% & 7.47 & 20.34 & 23.88 & 45.36 & 28.42 & 21.28 & 40.19 \\
\hline
\end{tabular}

* Las medias con la misma letra por columna no son significativamente diferentes de acuerdo con la prueba de Duncan para comparación múltiple de medias $(\mathrm{P}=0.05)$.

Contrariamente a lo ocurrido en la campaña anterior se observó diferencia estadística para el rendimiento total en peso, siendo las de mayor rendimiento la segunda y tercera época frente a la primera. Esto se debió probablemente a las precipitaciones pluviales que acompañaron al desarrollo del cultivo a partir del mes de noviembre de 1996.

No hubo diferencias significativas en el rendimiento de los cultivares en la primera época de siembra. Revolución tuvo su mayor rendimiento en la tercera época de siembra (10 de octubre) (Tabla 8), en cambio para el cultivar Imilla Negra y Gendarme el mayor rendimiento se obtuvo en la segunda época de siembra (24 de septiembre).

Tabla 8. Rendimiento total (t/ha) de tres cultivares de papa en tres épocas de siembra. Chinoli 1996-1997

\begin{tabular}{llll}
\hline Tratamiento & \multicolumn{3}{c}{ Rendimiento (t/ha) } \\
\cline { 2 - 4 } & Revolución & Imilla Negra & Gendarme \\
\hline $1^{\text {ra }}$ época & 18.98 & 14.63 & 13.10 \\
$2^{\text {da }}$ época & 18.67 & 24.02 & 18.10 \\
$3^{\text {ra }}$ época & 27.88 & 14.48 & 16.90 \\
\hline
\end{tabular}

D.M.S.: 6.57

C.V.\%: 20.34 
La fluctuación poblacional de la polilla de la papa (Phthorimaea operculella) se mostró errática. El primer áfido alado se capturó la semana en que se realizó el corte del follaje (Figura 4).

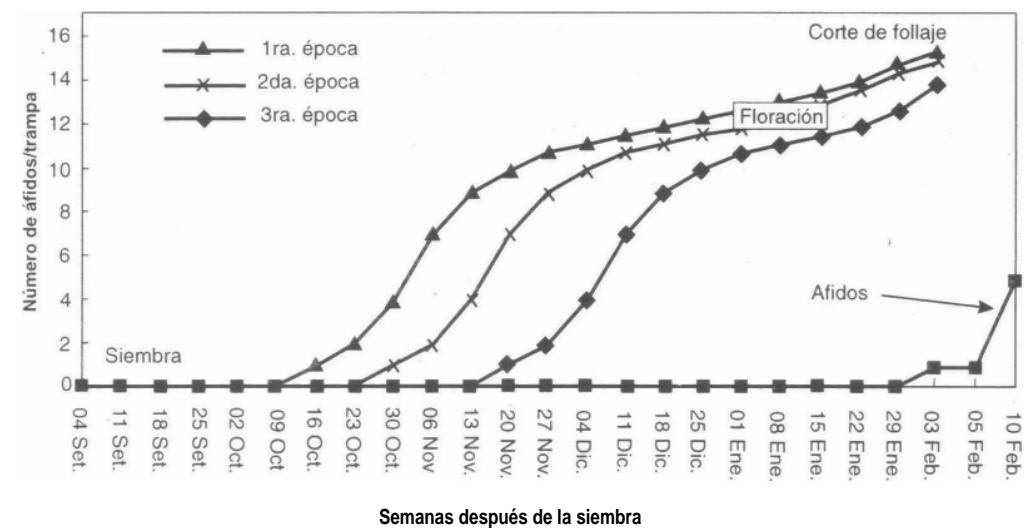

Figura 4. Fluctuación poblacional de áfidos en la parcela experimental de papa, en tres épocas de siembra. Chinoli 1996-1997.

Los resultados de serología (Tabla 9) muestran altas infecciones del virus PVY para los cultivares Imilla Negra y Gendarme en la segunda época de siembra (24 de septiembre) y no así para Revolución que mostró muy baja infestación sólo para la tercera época de siembra (10 de octubre ) de los virus PLRV y PVS. En Imilla Negra se detectó una baja y permisible incidencia (10 \%) de PVY en la-primera época de siembra (04 de septiembre).

Tabla 9. Incidencia de PLRV, PVY y PVS en tres cultivares de papa y tres épocas de siembra determinadas mediante DASELISA. Campaña 1996-1997

\begin{tabular}{|c|c|c|c|c|}
\hline \multirow[t]{2}{*}{ Cultivar } & \multirow[t]{2}{*}{ Época de siembra } & \multicolumn{3}{|c|}{$\%$ de virus detectado* } \\
\hline & & $\overline{\mathrm{PLRV}}$ & $\mathrm{PVY}$ & PVS \\
\hline \multirow[t]{3}{*}{ Revolución } & $1^{\mathrm{ra}}$ & 0 & 0 & 0 \\
\hline & $2^{\text {da }}$ & 0 & 0 & 0 \\
\hline & $3^{\text {ra }}$ & 3 & 0 & 3 \\
\hline \multirow[t]{3}{*}{ Imilla Negra } & $1^{\text {ra }}$ & 0 & 10 & 0 \\
\hline & $2^{\text {da }}$ & 0 & 17 & 3 \\
\hline & 3 & 0 & 0 & \\
\hline \multirow[t]{3}{*}{ Gendarme } & $1^{\mathrm{ra}}$ & 0 & 0 & 0 \\
\hline & $2^{\text {da }}$ & 0 & 41 & 0 \\
\hline & $3^{\text {ra }}$ & 0 & 0 & 0 \\
\hline
\end{tabular}

En plantas provenientes de una muestra de 30 tubérculos-semilla. 


\section{Discusión}

El adelanto de la fecha de siembra para mediados de septiembre (primera época de siembra) se presenta como una magnífica alternativa que permitirá la producción de semilla de alta categoría en la Estación Experimental Chinoli.

El monitoreo de las poblaciones de áfidos realizado en las campañas de 1993 a 1997 apoyan esta alternativa. Asimismo los resultados de serología confirmaron la alta sanidad de los tubérculos-semillas para esta época de siembra, escapando a la población de áfidos. Weemaels (10) en un estudio realizado entre enero y abril de 1991 en la E.E. Chinoli capturó alados de 24 especies de pulgones (9), entre los que predominaron Myzus persicae (61 \%), y en menor proporción Lipaphis erysimi (12\%), Brevicoryne brassicae (7\%), Aphis craccivora (5.2 \%) y Acyrthosiphon kondoi (5.2\%). Weemaels observó que la población de áfidos alados empezó a detectarse a fines de enero alcanzando un pico máximo a fines de marzo, de una población predominantemente de $M$. persicae, que correspondió con el fin de la floración en el cultivo de la papa. En el presente trabajo el monitoreo de las poblaciones de áfidos alados en cuatro campañas posteriores ha mostrado curvas poblacionales similares.

Las observaciones de Weemaels directamente en la vegetación a mediados de marzo de 1991, indicaron la presencia en el cultivo de papa de pequeños grupos de áfidos colonizantes compuestos de $70 \%$ de alados de las especies Acyrthosiphom pisum, Macrosiphum euphorbiae y Myzus persicae, principalmente su prospección en otros cultivos de la Estación Experimental, indicaron la ausencia de áfidos en cereales y quinua pero la presencia en leguminosas. En las hojas terminales de haba (Vicia faba) se observó colonias de Aphis craccivora, compuestas principalmente de individuos jóvenes. Grupos grandes de M. persicae y A. pisum, compuestos de $80 \%$ de adultos ápteros, fueron observados en el envés de las hojas de arveja. Sobre alfalfa se observó colonias de $A$. kondoi. En la mostaza silvestre (Brassica campestris L.) presente como maleza, se observaron colonias importantes en todos los estadios de desarrollo de M. euphorbiae y L. erysimi.

El M. persicae es el áfido más importante y eficiente para la transmisión tanto de PLRV como de PVY y la mayoría de los otros áfidos detectados observados son capaces de transmitir al PVY, por lo tanto esta información se debe tomar en cuenta para mejorar la producción de semilla en épocas de siembra adelantada, 
especialmente en lo que respecta a la presencia de cultivos de leguminosas y de la maleza $B$. campestris, los cuales deben evitarse en la zona de producción de semilla por lo menos dentro de los $500 \mathrm{~m}$ alrededor de las parcelas productoras de semilla. Además, deberá implementarse una rigurosa eliminación de posibles fuentes de áfidos vectores en almacenes de semilla próximos a las parcelas semilleras, así como extremar las medidas para evitar la diseminación por contacto del PVS y posiblemente una variante necrótica de PVY. La incidencia de la polilla fue errática y no mostró mayor problema en la producción de semilla. El adelanto en la época de siembra permitió evadir heladas que se presentaron posteriormente a la cosecha en las dos campañas de experimentación y que afectaron los cultivos sembrados en la época normal de cultivo.

Los rendimientos y número de tubérculos-semilla producidos, en la primera época de siembra para los tres cultivares fueron altamente satisfactorios pudiendo mejorarse probablemente con un mejor manejo del riego. Se lograron mejores rendimientos con el cultivar Revolución que es considerado un cultivar semi-precoz para las condiciones de la E.E. Chinoli, frente a los cultivares Imilla Negra y Gendarme considerados como tardío y semi tardío, respectivamente

La producción de tubérculos-semilla adelantando la época de siembra, incrementa los costos debido al riego suplementario, que en el presente trabajo se aplicó en tres oportunidades (pre-siembra, emergencia y un adicional auxiliar en el mes de noviembre) constituyendo un incremento en los costos de producción de alrededor del $5 \%$ que no se considera significativo para la producción de semilla.

Las observaciones visuales realizadas en los campos de producción de semilla de categoría básica II (Chinoli y Lagunillas) con la semilla de categoría básica I de la primera época de siembra cosechada en el presente trabajo, ratificaron la sanidad obtenida con el adelanto en la época de siembra habiendo sido considerada apta para certificación, de acuerdo a las normas vigentes en el proceso de certificación de semilla de papa en Bolivia.

Los resultados obtenidos en el presente trabajo nos permiten indicar que adelantar la época de siembra a mediados de septiembre, es una excelente alternativa también aplicable a las zonas productoras de tubérculos-semilla de papa en las pampas de Lequezana (Añawayo, Churru Mayu, Palca Pampa, Mosuna, y Lagunillas), bajo el sistema formal de producción, al contar las zonas mencionadas 
con terrenos libres de patógenos de suelo (nematodos) y dotación de riego suplementario. Esta alternativa permitiría contribuir a solucionar el problema de abastecimiento de semilla de altas categorías no disponible al presente, mediante la producción en la Estación Experimental de Chinoli y las pequeñas empresas semilleras de Mosuna y Lagunillas, permitiendo a su vez la remultiplicación de la semilla de calidad por las comunidades organizadas de Añawayo, Churru Mayu y Palca Pampa atendiendo así a la demanda de semilla de calidad en más de un $25 \%$ de las necesidades de los departamentos de Potosí, Chuquisaca, y Santa Cruz.

\section{Referencias Bibliográficas}

1. Benítez, C.E. 1995. Caracterización e "importancia de la enfermedad "planta morada" en cuatro variedades de papa. Universidad Autónoma 'Tomás Frías". Potosí - Bolivia.

2. Centro Internacional de la papa (CIP). 1996. Manual técnico sobre producción de tubérculos-semillas de papa. S-III-7-95. CIP. Lima, Perú.

3. Cisneros, F.V. 1995. Control de plagas agrícolas. 2da. Edición. AGCIS Electronics. La Molina. Lima - Perú.

4. Delgado, F.M. 1994. Niveles de fertilización y densidades de transplante de plántulas in-vitro de papa en invernadero Var. Revolución para la producción de tubérculos-semilla. Universidad Autónoma "Tomás Frías". Potosí - Bolivia.

5. Peters, D. 1987. Spread of viruses in potato crops. En: Viruses of potatoes and seed-potato production. J.A. de Bokx and J.A.H, van der Want (eds.). Pudoc, Wageningen. p. 126-145.

6. PROINPA. 1995. INFORME ANUAL 1994/1995. Programa de Investigación de la papa. Cochabamba, Bolivia.

7. PROSEMPA. 1996. Grupos oferentes de semilla, Memoria Modulo 5. Proyecto Nacional de Semilla de Papa. Cochabamba -Bolivia.

8. Raman, K.V. 1985. Transmisión de virus de papa por áfidos. Bol. Inf. Tec. No. 2. Centro Internacional de la Papa. Lima - Perú.

9. Remaudiere, G.; Weemaels, N.; Nicolás, J. 1991. Contribution á la connaissance de la faune aphidienne de la Solivie (Homoptera: Aphididae). Parasítica 47 (1):19-46. 
10. Weemaels, N. 1991. Contribution a Petude des pucerons vecteurs des principales viroses de la pomme de terre en Solivie. Thesis Ing. Agr., Faculté des Sciences Agronomiques de Gembloux, Belgique. 